\title{
The profitability of moving average trading rules in BRICS and emerging stock markets 证, 败访
}

\author{
Vinicius Amorim Sobreiro ${ }^{\mathrm{a}, *}$, Thiago Raymon Cruz Cacique da Costa ${ }^{\mathrm{a}}$, \\ Rodolfo Toríbio Farias Nazário a , Jéssica Lima e Silva ${ }^{\mathrm{b}}$, Eduardo Alves Moreirac ${ }^{\mathrm{c}}$, \\ Marcius Correia Lima Filho ${ }^{c}$, Herbert Kimura ${ }^{a}$, Juan Carlos Arismendi Zambrano d,e \\ a University of Brasília, Department of Management, Campus Darcy Ribeiro, Brasília, Federal District 70910-900, Brazil \\ ${ }^{\mathrm{b}}$ University of Brasília, Department of Accounting, Campus Darcy Ribeiro, Brasília, Federal District 70910-900, Brazil \\ ${ }^{\mathrm{c}}$ University of Brasília, Department of Economics, Campus Darcy Ribeiro, Brasília, Federal District 70910-900, Brazil \\ ${ }^{\mathrm{d}}$ Federal University of Bahia, Department of Economics, Rua Barão de Jeremoabo, 668-1154 Salvador, Brazil \\ e ICMA Centre, Henley Business School, University of Reading, Whiteknights, Reading RG6 6BA, United Kingdom
}

\section{A R T I C L E I N F O}

\section{Article history:}

Received 10 October 2015

Received in revised form 5 August 2016

Accepted 11 August 2016

Available online 9 September 2016

\section{JEL classification:}

G1

M1

M2

\section{Keywords:}

BRICS

Emerging markets

Moving average

Technical analysis

Trading systems

\begin{abstract}
A B S T R A C T
Technical analysis and trading systems have been widely used by practitioners in financial markets. Since some academic studies have highlighted that these tools can generate positive alphas when compared with a buy-and-hold strategy, we studied the main stocks of the BRICS and emerging markets. We considered the period from 2000 to 2015 and observed different combinations of moving average strategies and periods. The main results indicate that, for some countries, there is a combination of periods for moving averages producing better outcomes.
\end{abstract}

(ㄷ) 2016 Elsevier Inc. All rights reserved.

\section{Introduction}

Emerging markets have great importance for asset pricing and asset management theory as they provide additional diversification and risk mitigation to developed countries' portfolios (Glen, 2002; Chang, Lima, and Tabak, 2004; Buchanan, English, and Gordon, 2011; Kearney, 2012). As highlighted by Sinkovics, Yamin, Nadvi, and Zhang (2014), emerging economies could be important parts in international business. A thorough review of the literature of emerging markets is

\footnotetext{
We gratefully acknowledge useful comments and suggestions received from the editor and two anonymous referees.

解 This document was a collaborative effort.

* Corresponding author.

E-mail addresses: sobreiro@unb.br (V.A. Sobreiro), thiagorccc@gmail.com (T.R. Cruz Cacique da Costa), rodolfotio@gmail.com (R.T. Farias Nazário), jessica061291@hotmail.com (J. Lima e Silva), eduardofis06@gmail.com (E.A. Moreira), marcius_lima@hotmail.com (M.C. Lima Filho), herbert.kimura@gmail. com (H. Kimura), j.arismendi@icmacentre.ac.uk (J.C. Arismendi Zambrano).
} 
presented by Kearney (2012), who defined research trends that include, among others, data and methods, market efficiency, risk-adjusted returns, behavioural perspectives and topics that are impacted by technical analysis (TA) research. Furthermore, Kearney (2012) mentioned the different classifications used for defining and grouping emerging markets; the Morgan Stanley Capital Index and the Financial Times Stock Exchange Emerging Index are among the most used.

Differences between the French civil law and English common law based emerging markets were tested by Buchanan et al. (2011), who found that investing in the subset of French law based emerging markets provides an optimal level of diversification against the traditional strategy of investing in a broad set of emerging markets. They argue as well that the subset of BRIC economies (Brazil, Russia, China and India) provide efficient diversification and mention that studying the BRIC group as a subset is important given the potential political alliances that could arise as a result of their geopolitical conditions: while China and India are rural economies that have based their growth on exports of their industrial production, Brazil and Russia are commodity based economies. The acronym BRIC was first developed and employed by a group of economists at Goldman Sachs and more recently was expanded to BRICS by including South Africa (Li, Chen, and French, 2012).

One of the most important theories in finance is the "efficient market hypothesis" (EMH) of Fama (1970). The EMH theory states that random walk governs the behaviour of the markets, ruling out any benefit from technical analysis. However, recent studies by Lo (2004) suggest that markets are not efficient on a static base but are in a dynamic evolution going from inefficient markets to different levels of efficiency. One of the interesting aspects in testing technical analysis trading rules in emerging markets is that they have less developed financial systems that could result in lower levels of $E M H$ or even in inefficient markets. Mobarek and Fiorante (2014) tested the weak form of the EMH on the BRICS markets from September 1995 to May 2010 and found that they could be approaching a weak-form efficient market, as suggested by Park and Irwin (2007).

The fact that emerging markets can be non-efficient is one of the fundamental aspects of our research. A consequence of non-efficient markets is that trading strategies can generate significantly positive alphas. Lo (2004) presented a theory resulting from previous studies conducted on non-efficient markets: Lo and MacKinlay (1988) applied a test finding that prices in the market hardly follow a random walk; Lo and Wang (1995) developed an option pricing model considering that there is some predictability in the behaviour of the markets; and Lo, Mamaysky, and Wang (2000) defined and exhibited the foundations of technical analysis for studies on the "adaptive market hypothesis".

In our research we consider the BRICS countries and other emerging equity markets of importance for determining the profitability of moving average trading rules. The findings of Mobarek and Fiorante (2014) support the theory of "adaptive efficient markets" by Lo (2004), as moving from a non-efficient market condition to a "weak efficient market" condition in BRICS markets suggests a dynamic and inter-temporal condition.

Empirical research on TA is moving towards studies that test the high-frequency trading influence on the $E M H$ (Manahov, Hudson, and Gebka, 2014). Another stream of research in TA is exploring advanced trading rules that avoid "data-snooping", which is defined as the negative over-fitting effect produced by optimizing the parameters of the trading rule by repeated training with the same data Hsu, Hsu, and Kuan (2010). The TA effect in markets using simulations of agent based market models are also being studied to represent and describe the psychological and non-rational human behaviours effects in trading (Cristelli, 2014). An important factor when testing TA is the performance of the traders who use it. Hoffmann and Shefrin (2014) found that investors who apply TA as their main strategy in option trading are biased towards short-term speculative trading decisions that are sub-optimal in the long run.

Financial distress and financial shocks have an important effect on the EMH. As Han, Yang, and Zhou (2013) pointed out, in high-volatility markets technical indicators tend to be used by investors, generating alphas for risky portfolios. The reactions of emerging markets to shocks will be different to those of developed markets and their effects in the EMH are important. The impact of the 2008 financial crisis over the BRICS group was studied by Bianconi, Yoshino, and Machado de Sousa (2013), while Mensi, Hammoudeh, Reboredo, and Nguyen (2014) found by a quantile regression approach that BRICS markets are dependent on global and commodity markets and United States market volatility but are independent of United States economic policy uncertainty. Bond and forex emerging markets, and their relationship with equity emerging markets, are of importance during times of financial crisis. Broto (2013) studied market interventions during crises in four different Latin American emerging markets.

In general, it can be observed in the literature and in practice that TA is widely known and used among the participants of the financial market, as highlighted by Taylor and Allen (1992) and, more recently, by Fabozzi, Focardi, and Jonas (2007). However, in a different path from that of empirical conclusions, studies about indicators related to TA in the BRICS and emerging markets have not been carefully considered in the academic field (Teixeira and de Oliveira, 2010).

Considering this context, the main purpose of this study is to analyse the profitability of TA or, more specifically, of trading systems (TS) based on moving averages (MAs) in the BRICS and emerging stock markets because this methodology has been used in practice. In order to fulfil this purpose, a computational experiment was executed using the closing prices of the BRICS and emerging markets obtained from the Bloomberg ${ }^{\odot}$ and its performance was compared with the buy-and-hold strategy.

The main results of this study contribute both to academic researchers as well to market practitioners. From an academic viewpoint, the paper empirically verifies the propositions presented in several studies, for instance, Lo (2004) and Park and Irwin (2007) about the possibility of generating positive alphas, focusing on emerging markets. With regard to the practical 
aspects, this work presents results of profitability metrics exploring simple TS strategies, observing various combinations of $M A s$, over several years. More specifically, this work helps to answer the following questions:

1. Are there inefficient markets in the BRICS and emerging markets? If yes, can they provide profits?

2. Which types of MAs have shown better levels of performance in the BRICS and emerging markets?

3. What are the periods utilized in the MAs that had the best accomplishments?

4. Overall, did any of these options have better results than the buy-and-hold or long run passive strategy?

To answer previously raised questions, the paper is organized as follows. In Section 2 there is a brief description of the main aspects of $T A$ and MAs. In Section 3 the computational experiments are presented. In Section 4 we show the main results obtained. Finally, in Section 5 our findings and recommendations for future work are presented.

\section{Literature review}

\subsection{Technical analysis - TA}

The technical analyst studies the immediate past movements of stock prices with the aim of predicting the future movement of the stock. This means that traders operate on the principle that there will be a detectable effect on the price of the asset (Alexander, 1961; Reitz, 2006). As a complement to this concept, Murphy (1999) defines TA as the study of an asset, mostly through graphics, in order to predict its future price while considering follows assumptions:

1. Prices reflect all relevant information;

2. Price changes move in trends or are not totally random; and

3. The history of the prices tends to repeat itself.

Vanstone and Finnie (2009) state that TA gained prominence with the work of Charles Dow. More specifically, these authors indicate that Charles Dow wrote many papers related to stock prices in the Wall Street Journal. According to Cowles (1933), William Peter Hamilton succeeded Charles Dow as editor at the Wall Street Journal and he kept this position until his death in 1929. In the 26 years that he was in this job, Hamilton wrote 255 editorials in which he presented predictions of the stock market according to the Charles Dow studies.

The publications of Dow and Hamilton are considered to be the starting point of $T A$, although, as Vanstone and Finnie (2009) highlighted, there is evidence that TA started centuries before these famous analysts with Munhehisa Homma in Japan. However, in terms of academic publications, Cowles (1933) is one of the oldest academic papers that addresses TA. On the other hand, the research of Alexander (1961), Fama and Blume (1966), Levy (1967), Jensen and Benington (1970) and Fama (1991) indicates that stock prices follow the theory of the random walk; that is, the $E M H$ is valid.

The theory of the $E M H$ can be easily found in current finance literature because academics recognize that changes in prices are independent and reflect all available information or, in other words, the $E M H$ is the theory that explains stock prices (Zhu and Zhou, 2009). Consequently, considering the $E M H$, the investment in additional information cannot provide financial advantages. In contrast, Grossman and Stiglitz (1980) offered a model in which the prices reflect all available information only partially. In this case, those who invest in information will receive compensation. The results reveal that when the $E M H$ is true and the information is expansive competitive markets fail.

On the other hand, Lo and MacKinlay (1988) utilized variance estimators and proved the non-existence of the random walk in the stock market, using as their sample the NYSE-AMEX index. This is in accordance with the findings of Brown and Jennings (1989). Furthermore, Brock, Lakonishok, and LeBaron (1992) used popular strategies to validate the predictive power of the price history. In their study, the MAs and the trading-range breaks provided excess returns. It is important to highlight that the method shown in Brock et al. (1992) has contributed substantially to TA as it has been used in other papers, such as Hudson, Dempsey, and Keasey (1996), Parisi and Vasquez (2000), Kwon and Kish (2002) and Marshall and Cahan (2005).

$T A$ is composed of several tools that are used as indicators and oscillators, amongst which MAs stand out as highlighted by Zhu and Zhou (2009). Wei, Cheng, and Wu (2014) commented that MAs are the trading rules that are most widely known and used by practitioners and financial traders in the markets. A probable explanation for this wide use is the fact that the MAs method is easily understandable. The MAs' purpose is to identify the trends towards changes in prices, with the buy signal occurring when the current stock price is higher than the MAs and the sell signal occurring when the opposite is the case (Murphy, 1999; Kuo, 2002; Wei et al., 2014). Consequently, the MAs have been used as the guiding principle in many TSs, which in turn is a set of rules as shown in Algorithm 1 that determine autonomously the buy and sell orders without the supervision of a person (Jaekle and Tomasini, 2009). 


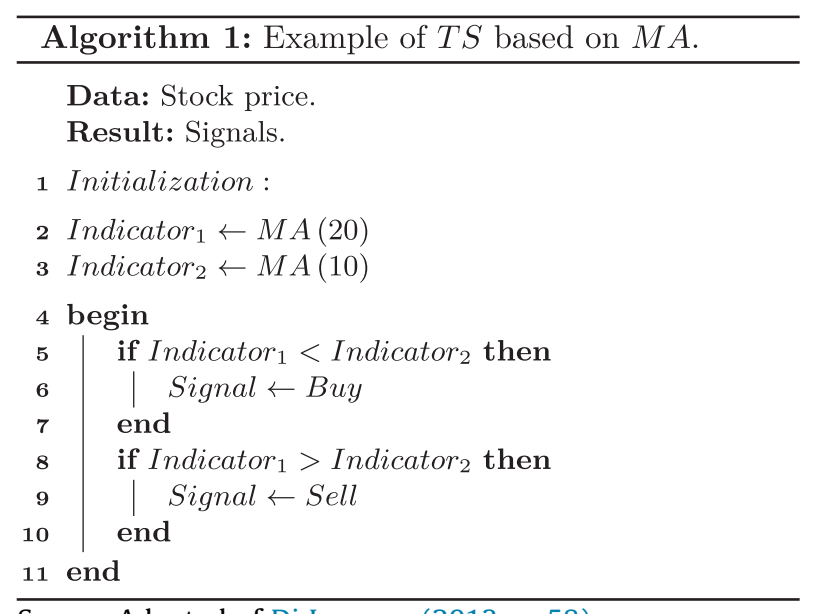

Source: Adapted of Di Lorenzo (2013, p. 58).

In a nutshell, Algorithm 1 generates buy or sell signals based on two moving averages of stocks prices. When the first indicator, the moving average of 10 periods, gets higher than the second indicator, the moving average of 20 periods, a buy signal is flagged. A sell signal occurs when the second indicator gets higher than the first.

Transaction costs are an important topic in the TA predictive power discussion. Alexander (1961), Fama and Blume (1966) and Jensen and Benington (1970) concluded that TA strategies do not generate significant results in comparison to the buyand-hold strategy when transaction costs are taken into account. However, more recent studies differ on this conclusion. Fong and Yong (2005), utilizing the simple moving average (SMA) with digital industry stocks, and Ellis and Parbery (2005), utilizing the adaptive moving average ( $A M A)$ with different markets indexes, found insignificant differences in results when the transaction costs were considered. On the other hand, Teixeira and de Oliveira (2010), testing the TA predictive capacity in the Brazilian market, verified that the earnings are superior to those generated by the buy-and-hold strategy, even with the transaction costs.

\subsection{Moving averages - MAs}

In their simplest form, MAs can be defined as the sum of the latest stock prices divided by the number of stock prices (or a lagging indicator used as a smoothing device to reduce the effect of noise to indicate the new trend of prices (Murphy, 1999; Ellis \& Parbery, 2005; Moon \& Kim, 2007; Zhu \& Zhou, 2009)). Although there is a wide range of different types of MAs, including the weighted moving average (WMA), Kaufman's adaptive moving average (KAMA), the variable index dynamic average (VIDYA) and the MESA adaptive moving average (MAMA), the simple and the exponential moving averages are the ones most used by the practitioners and in TS to provide buy and sell signals. This is because they can be easily quantified, calculated, tested and understood. In a more specific way, according to Ellis and Parbery (2005) and Metghalchi, Chang, and Marcucci (2008), the simple moving average (SMA) can be calculated as shown in Eq. (1):

$$
S M A_{n}=\frac{1}{k} \times \sum_{t=n-k+1}^{n} P_{t}
$$

where:

$k$ is the number of periods included in the SMA calculation;

$n$ is the relative position of the current period observed; and

$P_{t}$ is the closing price of the stock in the $t$ period.

On the other hand, the exponential moving average (EMA) is better suited to locating markets trends than the SMA (Appel, 2005). According to Tung and Quek (2011), the EMA can be calculated as shown in Eq. (2).

$$
E M A_{n}=\left(\frac{2}{k+1}\right) \times P_{t-1}+\left(1-\left(\frac{2}{k+1}\right)\right) \times E M A_{n-1}
$$

where:

$k$ is the number of periods included in the EMA calculation;

$n$ is the relative position of the current period observed;

$P_{t-1}$ is the closing price in the previous period; and

$E M A_{n-1}$ is the $E M A$ calculated in the previous period. 


\section{Computational experiments}

\subsection{Specifications}

\subsubsection{Moving averages - MAs}

In this study, for the SMA and the EMA, two MAs were used simultaneously, one with $k$ periods superior and the other with $k$ periods inferior. At the moment in which the shorter $M A$ value is superior to the longer $M A$ there will be a buy order, otherwise there will be a sell order. According to Pavlov and Hurn (2012) and Ellis and Parbery (2005), the MAs recommendations are:

Buy: when the short MA crosses the long MA from below; and

Sell: when the short $M A$ crosses the long $M A$ from above.

To create trading orders, all possible combinations between these two MAs (Scenarios: SMA-SMA, EMA-EMA, and SMA$E M A)$ were tested considering the notation and the intermissions presented in Table 1:

\subsubsection{Data and stocks}

The main data used in this study were the closing prices of 4,021 stocks, as presented in Table 2 . The entire history series of closing prices of all these stocks was from January 3, 2000 to December 30, 2015. All the data were obtained from the Bloomberg ${ }^{\mathcal{C}}$.

Brokerage fees and stop losses were not considered in this study because each country has a different manner in which they are applied. Furthermore, implementation shortfall (IS), or slippage, was not considered because the trades should only occur on the following business day after considering the closing price of stocks. The IS represents the total cost or the friction associated with executing the trade or investment idea (Kissell, 2013).

\subsection{Trading system - TS}

The TS used in this study was built using Visual Basic for Applications ${ }^{\odot}$ and all simulations were made using Microsoft Office Excel $^{\odot}$. Fig. 1 displays the main user interface developed to test the TS.

In a nutshell, the central idea of the TS is to execute buy and sell operations after taking into account the crossing of two different periods' MAs, as shown in Algorithmn 2. The starting capital used was 10,000.00 currency units for all stocks. Thus, for example, when the MAs crossing indicates, for the first time, a buy signal, the TS will buy the maximum possible number of stocks. When a sell signal is identified by the MAs, the TS will sell all stocks considering the closing price of each stock. The resulting capital will be used in the next buy until the end of the series. It is important to highlight that no short selling will take place.

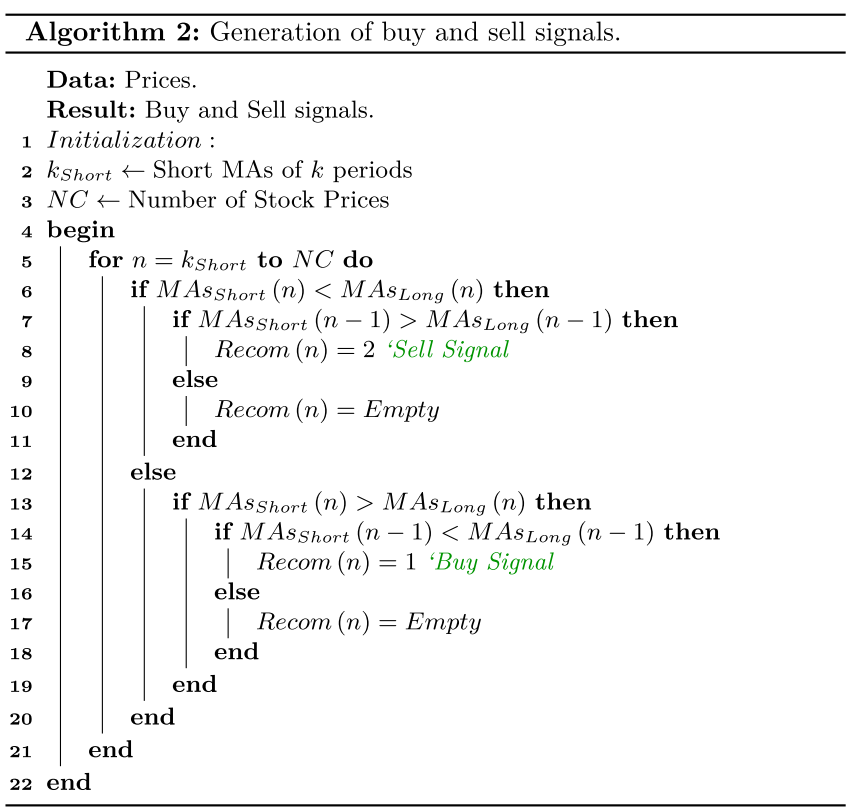

It is worth noting that the TS used in this study tests results from different combinations of various moving averages strategies, and does not follow any learning process or make any prediction over time. Thus, differently from studies that make predictions of futures prices based on development and validation samples, our research does not necessarily involve an in-sample and out-of-sample. Therefore, the application of metrics (MSA, RMSE and MAPE) commonly used in forecasting processes is not direct adequate to the study. 
More precisely, the TS is divided into interface and computational stages. The first stage, interface, is the communication that the user has with the TS. At this stage the investment conditions and calculation of the MAs are defined for the stocks studied. In the second stage all MAs values are calculated, the negotiations are realized and the main results are recorded in a spreadsheet and shown to the user. The process structure of the TS is presented in Fig. 2 and the main set of instructions is shown in Algorithm 3.

This process is followed by the computational stage. As the name suggests, this last step is fully automated, with the values of the MAs being calculated and thereafter being used for the negotiations. Finally, after calculating the buy-and-hold and performance index, a spreadsheet is completed containing all the simulation results. The TS is presented in Fig. 2.

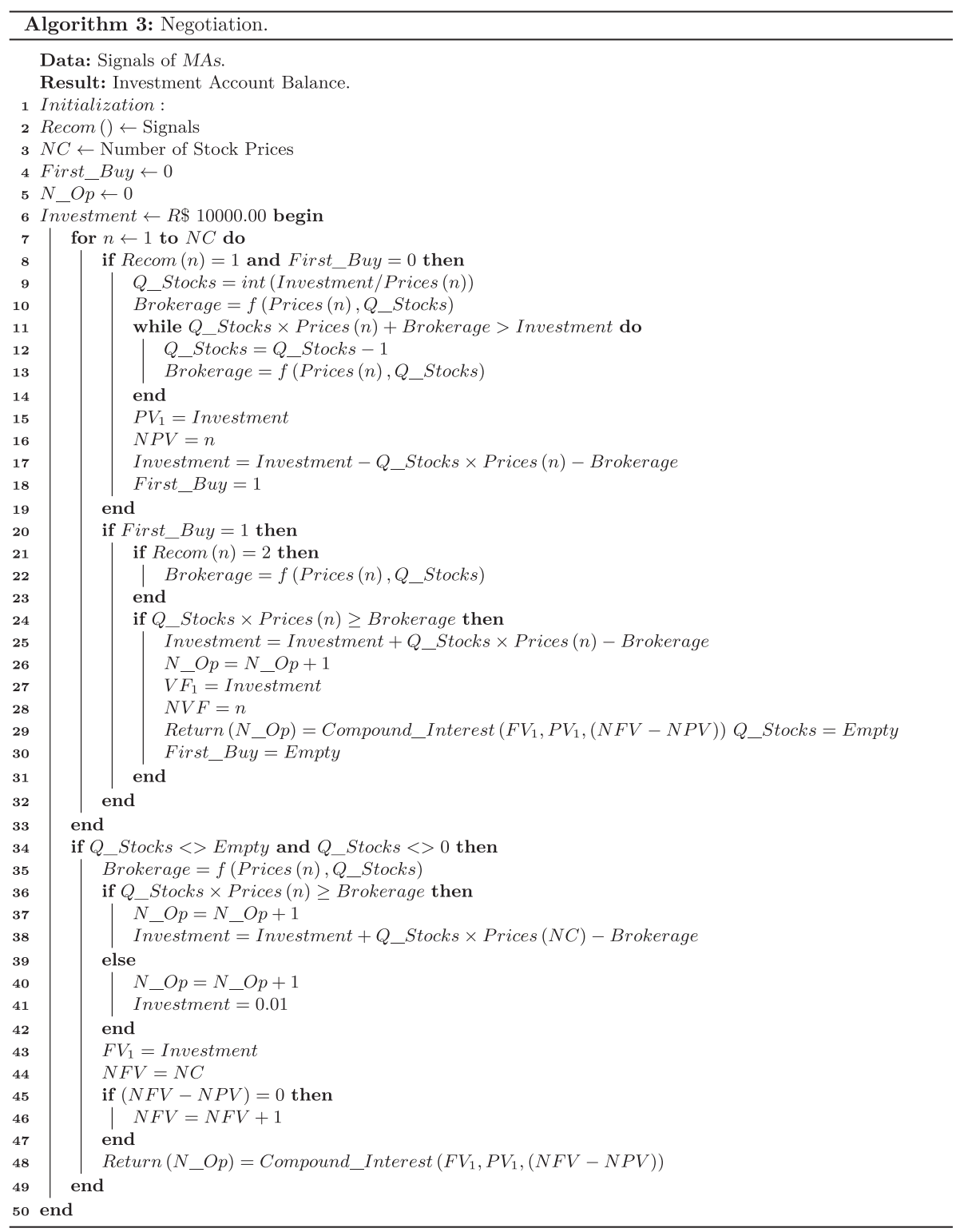

\subsection{Performance index}

In order to measure the performance of the studied techniques, we observe these methods considering the ratio ( $h$ ) between the average return $(\bar{R})$, calculated as shown in Algorithm 3, and the standard deviation (SD) for each stock, as presented in Eq. (3).

$$
\hbar=\frac{\bar{R}}{S D(\bar{R})}
$$


Table 1

Notation and periods of $k$.

\begin{tabular}{ll}
\hline MAs & Notation and period \\
\hline Short & $k_{\text {Short }} \in \mathbb{N} \mid 10 \leqslant k_{\text {Short }} \leqslant 40$ \\
Long & $k_{\text {Long }} \in \mathbb{N} \mid 100 \leqslant k_{\text {Long }} \leqslant 150$
\end{tabular}

Table 2

Number of stocks by market.

\begin{tabular}{ll}
\hline Market & Number of stocks \\
\hline Argentina & 19 \\
Brazil & 199 \\
Chile & 34 \\
China & 2,570 \\
Colombia & 34 \\
India & 756 \\
Mexico & 47 \\
Peru & 27 \\
South Africa & 237 \\
Russia & 66 \\
Jamaica & 32 \\
Total & 4021 \\
\hline
\end{tabular}

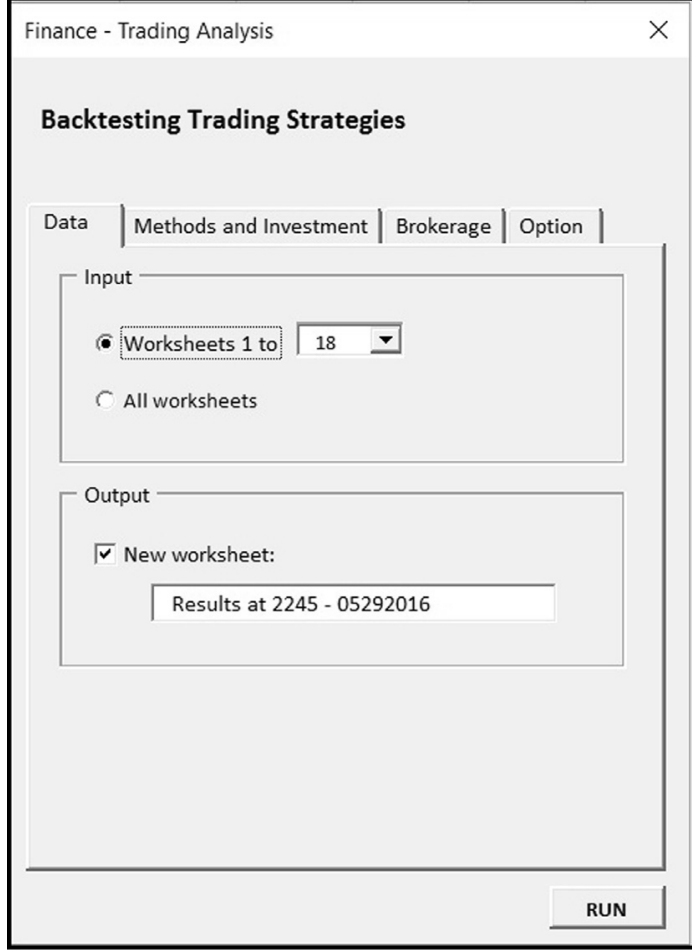

Fig. 1. Trading system's interface.

where: $\bar{R}$ represents the total return of the simulation conducted; and $S D(\bar{R})$ represents the total standard deviation of the simulation conducted.

In summary, an example of the calculation of the value of $\hbar$ is presented in Table 3 to enable a better understanding of performance indexes. Consequently, in order to compare the results obtained by TA with the buy-and-hold strategy, $\hbar$ is used in calculating the relative average deviation $(R A D)$, which represents the distance of each result from the best known value. Considering the studies of Framinan, Nagano, and Moccellin (2009), Nagano, da Silva, and Lorena (2012), Sobreiro and Nagano (2012) and Sobreiro, Mariano, and Nagano (2013), the RAD is calculated as follows in Eq. (4), it is important highlight that the TA shows a shorter value of $R A D$ is the best. 


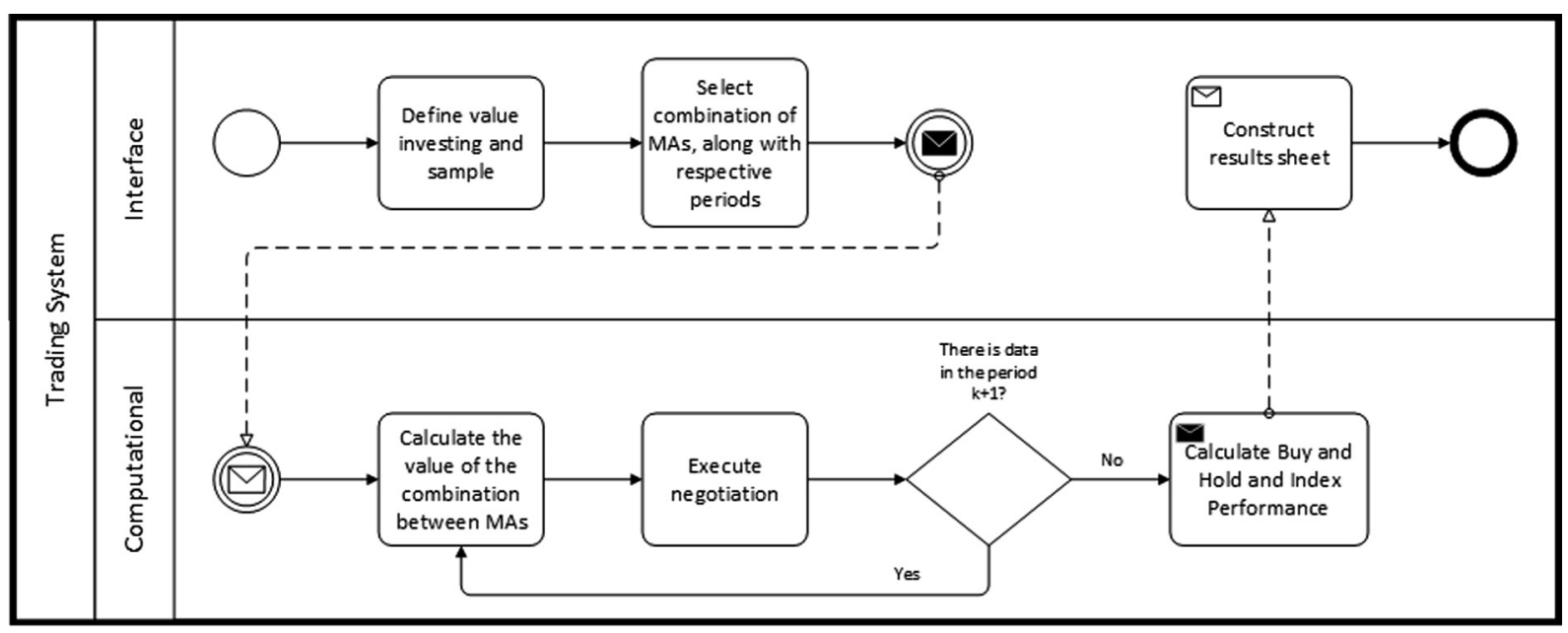

Fig. 2. Approach of trading system.

Table 3

Example of the calculation of $\hbar$.

\begin{tabular}{|c|c|c|c|c|c|c|c|c|c|c|c|}
\hline Stock & Date $^{a}$ & Signal & Traded quantity $^{\mathrm{b}}$ & Close price & Present value & Future value & Period & Return $(R)^{\mathrm{c}}$ & $\bar{R}^{\mathrm{d}}$ & $\mathrm{SD}^{\mathrm{e}}$ & Ratio $\hbar^{\mathrm{f}}$ \\
\hline \multirow[t]{6}{*}{$\operatorname{Stock}_{\beta}$} & $05 / 10 / 20 X X$ & Buy & 4.00 & 10.00 & 40.00 & & 9 & $1808 \%$ & $1057 \%$ & $0.586 \%$ & 1.804 \\
\hline & $05 / 19 / 20 X X$ & Sell & 4.00 & 11.75 & & 47.00 & & & & & \\
\hline & $05 / 22 / 20 X X$ & Buy & 4.00 & 9.80 & 39.20 & & 10 & $0.440 \%$ & & & \\
\hline & $06 / 01 / 20 X X$ & Sell & 4.00 & 10.24 & & 40.96 & & & & & \\
\hline & $06 / 17 / 20 X X$ & Buy & 4.00 & 11.12 & 44.48 & & 7 & $0.973 \%$ & & & \\
\hline & $06 / 24 / 20 X X$ & Sell & 4.00 & 11.90 & & 47.60 & & & & & \\
\hline
\end{tabular}

a Considering $M M / D D / Y Y Y Y$.

b This value does not admit decimal position values.

c The return was calculated on a compound basis.

d This value was calculated considering $\bar{R}=\sum p(R) \times R$ or $\frac{9}{(9+10+7)} \times 1.808 \%+\frac{10}{(9+10+7)} \times 0.440 \%+\frac{7}{(9+10+7)} \times 0.973 \%$.

e This value was calculated considering $S D(\bar{R})=\sqrt{\left(\sum p(R) \times R^{2}\right)-(\bar{R})^{2}}$.

${ }^{\mathrm{f}}$ This value was calculated considering $\frac{\bar{R}}{S D(R)}$.

Table 4

Results regarding the $R A D$ and the comparison between the returns and the Buy-and-Hold strategy.

\begin{tabular}{|c|c|c|c|c|c|c|c|}
\hline \multirow[t]{2}{*}{ Market } & \multirow[t]{2}{*}{ Number of stocks } & \multicolumn{2}{|c|}{ SMA-SMA } & \multicolumn{2}{|c|}{ EMA-EMA } & \multicolumn{2}{|c|}{ SMA-EMA } \\
\hline & & RAD & Abnormal returns (\%) & RAD & Abnormal returns (\%) & RAD & Abnormal returns (\%) \\
\hline Argentina & 19 & 17.72 & 69.69 & 42.30 & 73.92 & 43.44 & 73.92 \\
\hline Brazil & 199 & 203.00 & 62.00 & 120.65 & 61.95 & 63.12 & 61.57 \\
\hline Chile & 34 & 13.97 & 41.99 & 51.00 & 39.17 & 18.30 & 43.75 \\
\hline China & 2570 & 222.56 & 40.98 & 327.26 & 43.93 & 141.20 & 42.00 \\
\hline Colombia & 34 & 19.16 & 36.64 & 35.45 & 39.70 & 24.34 & 39.36 \\
\hline India & 756 & 78.30 & 55.07 & 40.25 & 52.19 & 46.04 & 53.76 \\
\hline Jamaica & 32 & 8.24 & 28.23 & 96.01 & 17.83 & 311.94 & 19.42 \\
\hline Mexico & 47 & 17.00 & 47.45 & 24.74 & 50.11 & 25.87 & 50.12 \\
\hline Peru & 27 & 9.74 & 75.41 & 21.52 & 73.29 & 30.97 & 71.49 \\
\hline Russia & 66 & 15.32 & 64.89 & 43.10 & 63.97 & 43.32 & 66.74 \\
\hline South Africa & 237 & 54.38 & 37.22 & 34.51 & 41.42 & 73.93 & 38.30 \\
\hline Arithmetic average: & - & 59.95 & 50.87 & 76.07 & 50.68 & 74.77 & 50.95 \\
\hline
\end{tabular}

$$
R A D=\frac{\left(f(h)-f^{*}\right)}{f^{*}}
$$

where:

$f(h)$ is the target function or $\hbar$; and

$f^{*}$ is the best known value of $\hbar$. 


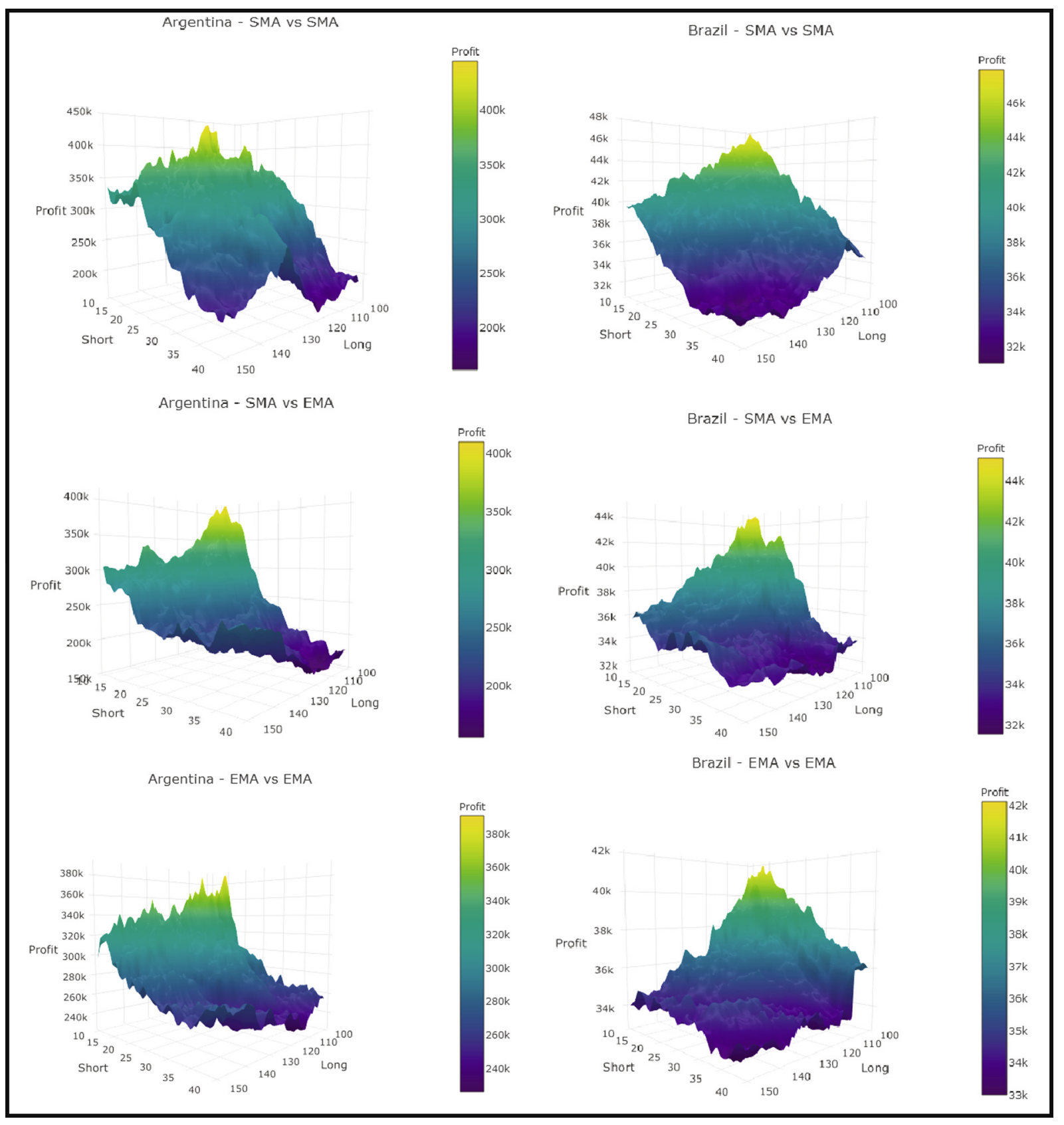

Fig. 3. Argentina and Brazil results'.

The results of the simulation are shown in the following section and an analysis of the graphs showing the final values found are obtained with the intention of investigating the patterns of the construction of the averages periods in the stock markets under review.

\section{Results}

The TS generated $19.071 .603^{1}$ results with the analysis of $1581^{2}$ distinct combinations of periods of the averages in 4021 stocks from the BRICS and emerging markets. In this section we study the MAs' performance and analyse the concentration of the generated results.

\footnotetext{
$11581 \times 4021 \times 3$ Scenarios.

$2(40-10+1)=31$ and $(150-100+1)=51 .(31 \times 51)=1581$ (Please, see Table 1$).$
} 


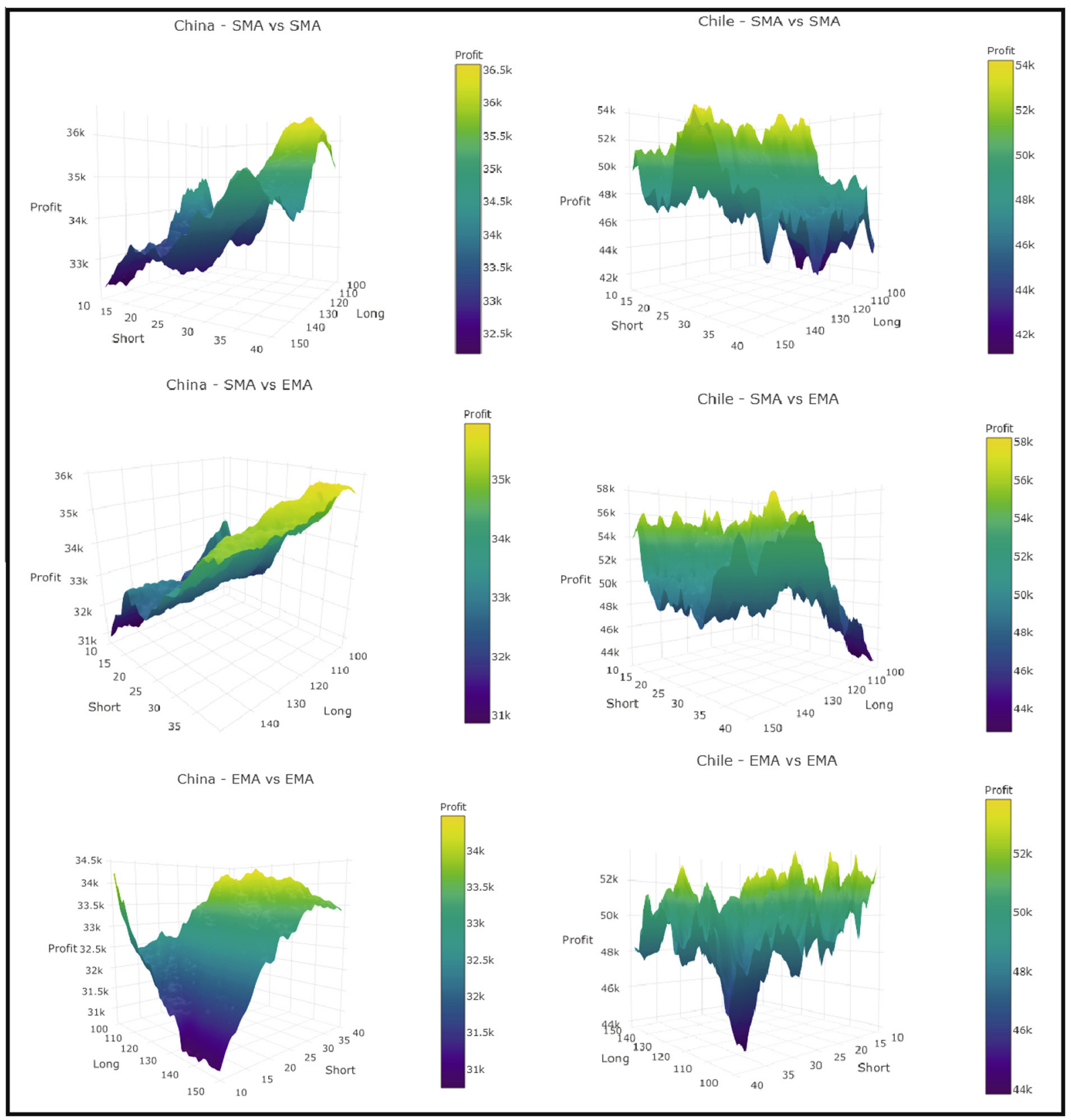

Fig. 4. China and Chile results'.

\subsection{Study of the MAs' performance}

Table 4 reports the results of the $R A D$ study and presents the percentage of the returns that are better than the final values of the buy-and-hold strategy.

Regarding the RAD indicator, Table 4 presents the evidence for relevance of the combination SMA-SMA in the sample. In all countries, but Brazil, China, India, and South Africa SMA-SMA led to better results. In this sense, one can affirm that, in most countries, the usage of such a combination generated a higher return to the investor assuming a minor risk when compared to other techniques.

Within the scope of the RAD analysis, there was a lower performance of the combinations EMA-EMA and SMA-EMA in the studied stocks. The EMA-EMA performance only exceeded the others in the Indian and South African stock markets and 


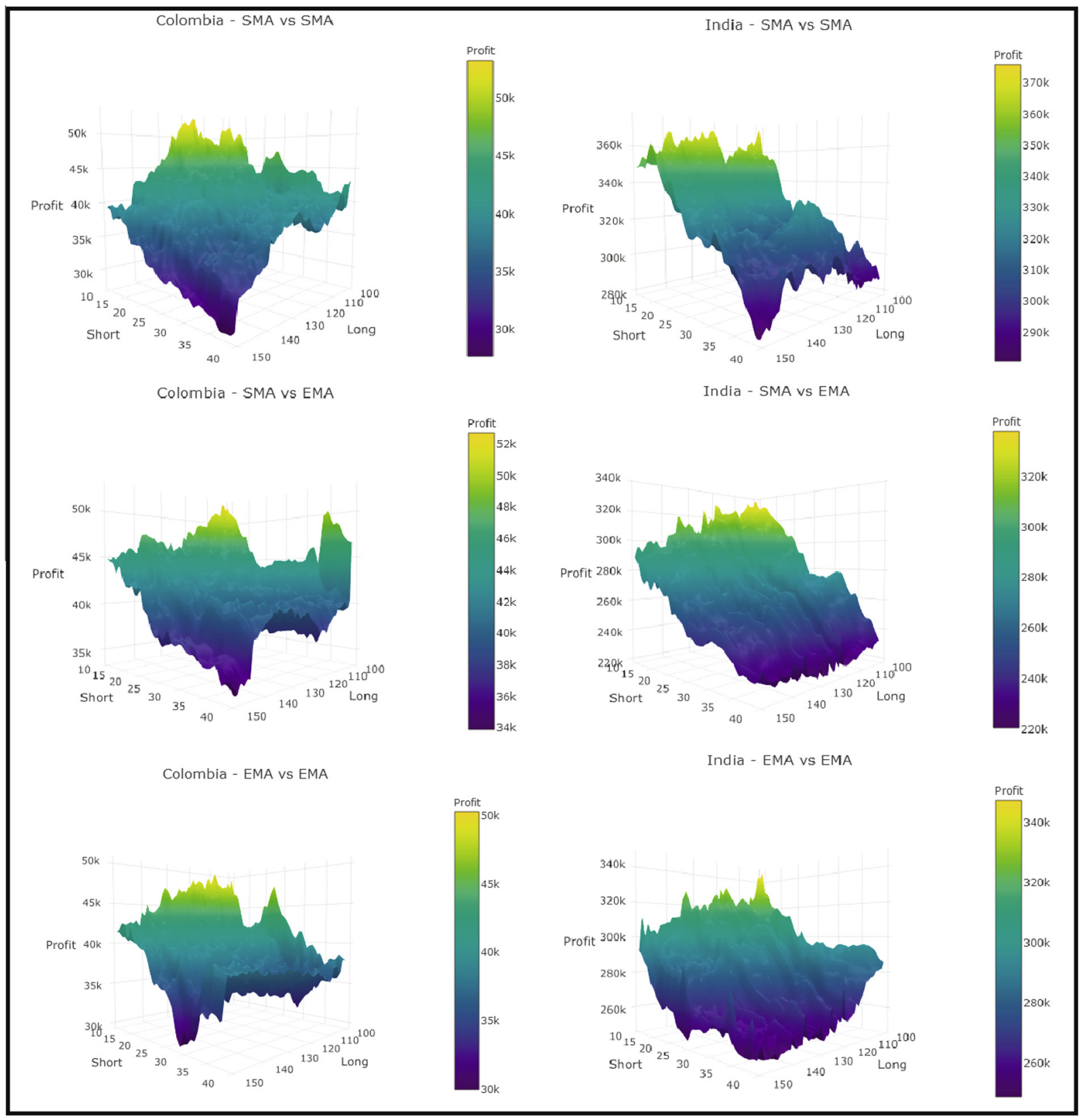

Fig. 5. Colombia and India results'.

showed little efficiency in the returns and risk ratios in other markets. The SMA-EMA combination only exceeded the other combinations in the Brazilian and Chinese stock markets.

We can see from Table 4 that there is little efficiency of the studied MAs strategies in comparison to the buy-and-hold strategy, which is very similar to the results obtained by Alexander (1961) and Ellis and Parbery (2005). The Jamaican stock market stand out with its smaller return compared to the buy-and-hold strategy. However, for some markets, such as Argentina's and Peru's, the MAs presented a larger number of higher results than the buy-and-hold strategy.

We can see by analysing the results of Brazil, Argentina and Jamaica that there is a major tendency for the concentration of higher returns in the areas where the long moving averages take values of between 120 and 100 days and the short moving averages take values between 30 and 10 days. This result may signal that the strategies concerning those markets are susceptible to lower period trends taking place in the market. For the other countries, there is not a distinguishable pattern to identify long and short MAs that lead to better outcomes. 


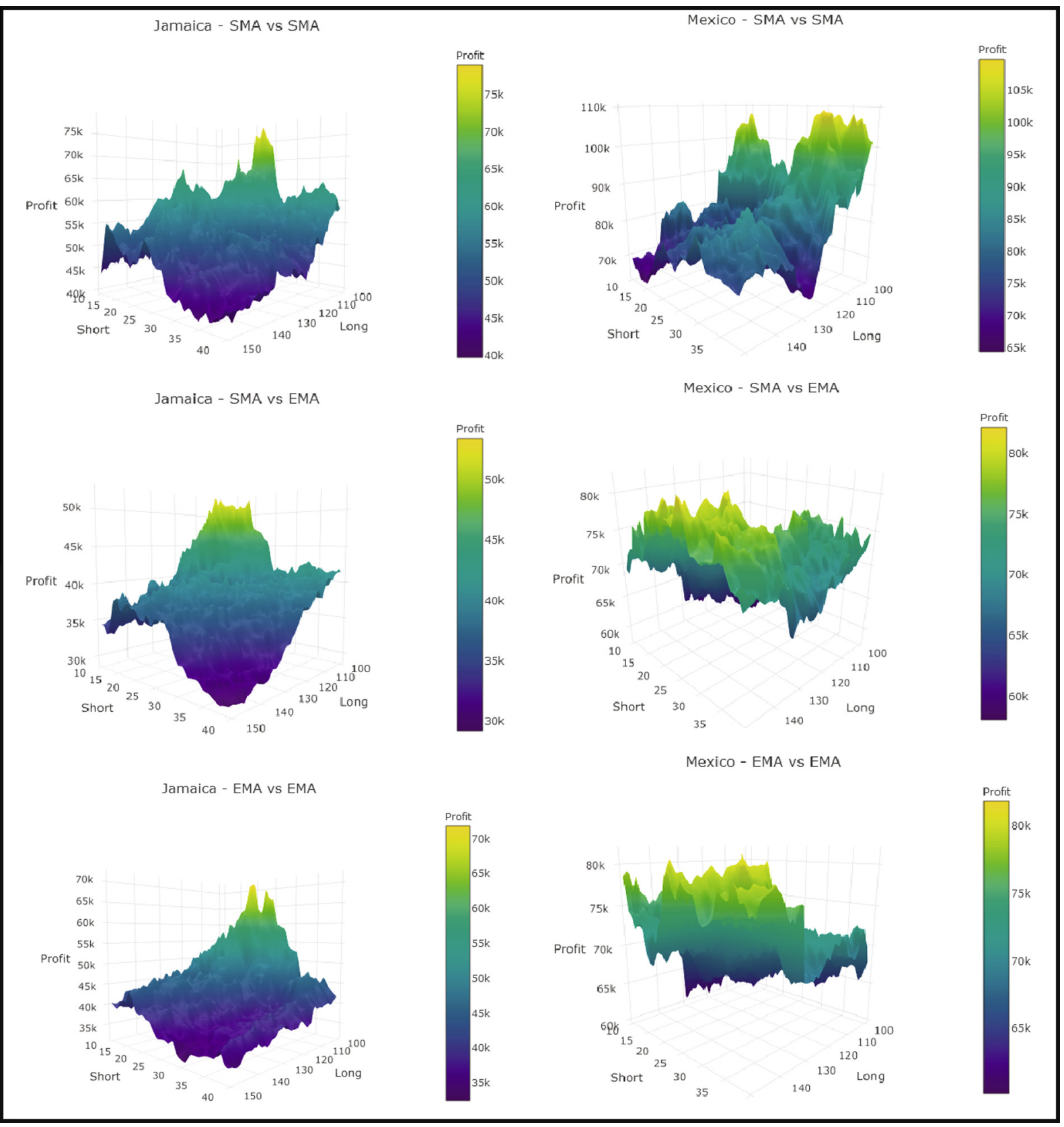

Fig. 6. Jamaica and Mexico results'

There are countries that are in the middle of this classification. For instance, in Mexico, the optimal interval for MAs may not be close to either of the extreme values or each moving average strategy analysed, which makes it difficult to categorize the market with one label; that is, shorter trends or longer trends. Results for different combinations of short and long MAs are depicted in Figs. 3-8.

However, as mentioned earlier, there were countries with different patterns for each of the types of strategies used, suggesting that strategies that fit the data better have a larger quantity of higher returns as they filter more precisely the excess market noise. Another possible explanation for these different moving average period patterns is that, as Alexander (1961) and Fama and Blume (1966) stated, there might be the presence of a random walk in the data, making it difficult to extract any pattern from the historic prices of the stocks. For that reason, the periods of the optimal moving averages can change drastically with changes in the intensity of the random walk in the data. 


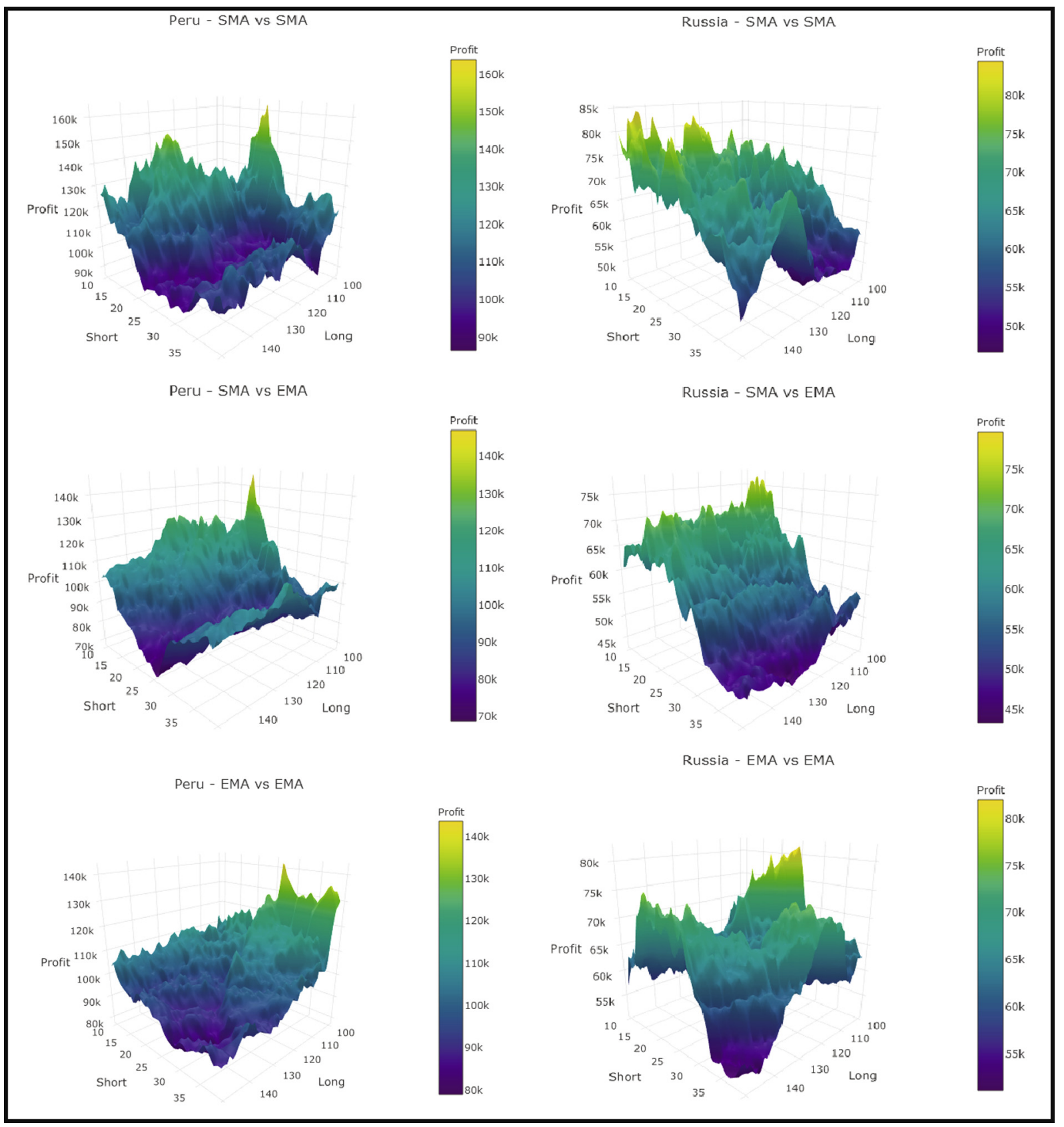

Fig. 7. Peru and Russia results'.

\section{Conclusions}

Through the construction of a TS, this study analysed the behaviour of three distinct combinations of MAs based on the use of SMA and EMA in the stocks histories of the BRICS and emerging markets for the period from 2000 to 2015 . Many combinations of the periods and moving average strategies analysed were used for the calculation of these MAs.

The results show the good performance of the combinations based on the SMA-SMA. Thus, one can affirm that, through the study of the $R A D$, based on the ratio between the return and its standard deviation, the SMA-SMA strategy generated the best risk and return ratio involving the study methods. Moreover, we point out that there is a concentration of the higher results in some particular combinations of periods for the moving averages calculations in the studied markets, e.g., long MAs between from 100 to 120 and from 10 to 30. However, this combination is not static for all of the countries, which makes it difficult to detect a pattern in the periods of the moving averages. Each market has its own set of optimal periods. As Lo 


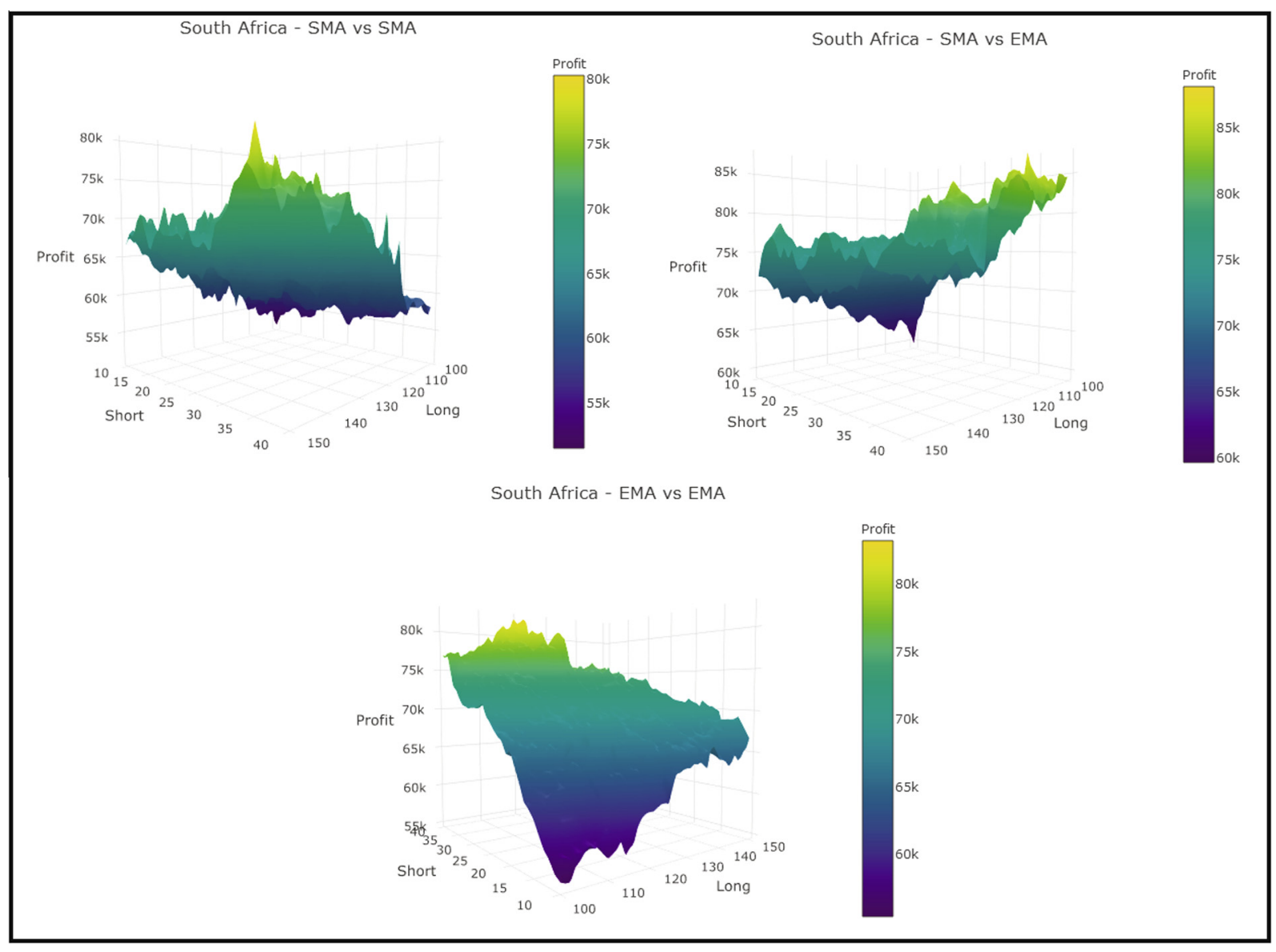

Fig. 8. South Africa result's.

(2004) stated, the results show that emerging markets can have different levels of efficiency and technical indicators to enable moving averages to be applied in trading strategies to generate profits in these markets. In general, we find that moving averages are still beaten by the buy-and-hold strategy in most markets, with a few exceptions like Brazil, Russia and Argentina (Ellis and Parbery, 2005).

Although we have advanced the discussion about the profitability of TA in the BRICS and other emerging countries, we need to highlight the following limitations of our study, which could be explored by other researchers in future studies:

- Recent studies, for instance, Ratti and Vespignani (2015), have investigated the influence of commodity prices on the economies of emerging markets and BRICS. As many countries considered in this study are producers of commodities in the energy, agriculture, minerals and materials, precious metals and raw materials commodities sector, we recommend that future studies thoroughly analyse the impact of medium and long-terms trend of commodity prices in stock prices and consequently in technical analysis strategies; and

- Transaction cost is an important factor in measuring the profitability of trading strategies. Due to the computational cost of performing our experiments for all 4,021 stocks, using an extended time frame from 2000 to 2015, we were not able to run the simulations using transaction costs. In this context, we recommend that the impact of transaction costs on TS be the focus of future studies.

Finally, the results shown in this study can be of great value to investors who target automatic trading systems when using TA in the BRICS and emerging markets. For future studies, because the literature does not reflect careful studies about the indicators related to technical analysis in emerging markets (Teixeira and de Oliveira, 2010), we suggest the application of a bigger set of technical analysis methods and the mixing of them to generate more complex trading rules in those markets. Another suggestion is to use different time periods to study how the indicators behave in different economic scenarios for emerging markets. 


\section{Acknowledgments}

This research was supported in party by a grant from the Brazilian National Research Council (CNPq).

\section{References}

Alexander, S. S. (1961). Price movements in speculative markets: Trends or random walks. Industrial Management Review, 2(2), 7-26.

Appel, G. (2005). Technical analysis: Power tools for active investors. Financial Times Prentice Hall.

Bianconi, M., Yoshino, J. A., \& Machado de Sousa, M. O. (2013). BRIC and the U.S. financial crisis: An empirical investigation of stock and bond markets. Emerging Markets Review, 14(1), 76-109. http://dx.doi.org/10.1016/j.ememar.2012.11.002.

Brock, W., Lakonishok, J., \& LeBaron, B. (1992). Simple technical trading rules and the stochastic properties of stock returns. The Journal of Finance, 47(5), 1731-1764. http://dx.doi.org/10.1111/j.1540-6261.1992.tb04681.x.

Broto, C. (2013). The effectiveness of forex interventions in four Latin American countries. Emerging Markets Review, 17(1), 224-240. http://dx.doi.org/ 10.1016/j.ememar.2013.03.003.

Brown, D. P., \& Jennings, R. H. (1989). On technical analysis. Review of Financial Studies, 2(4), 527-551. http://dx.doi.org/10.1093/rfs/2.4.527.

Buchanan, B. G., English, P. C., \& Gordon, R. (2011). Emerging market benefits, investability and the rule of law. Emerging Markets Review, 12(1), 47-60. http://dx.doi.org/10.1016/j.ememar.2010.09.001.

Chang, E. J., Lima, E. J. A., \& Tabak, B. M. (2004). Testing for predictability in emerging equity markets. Emerging Markets Review, 5(3), 295-316. http://dx.doi. org/10.1016/j.ememar.2004.03.005.

Cowles, A. (1933). Can stock market forecasters forecast? Econometrica, 1(3), 309-324. http://dx.doi.org/10.2307/1907042.

Cristelli, M. (2014). Complexity in financial markets. No. 978-3-319-00722-9 in Springer Theses. Springer International Publishing.

Di Lorenzo, R. (2013). Basic technical analysis of financial markets. Springer Milan. http://dx.doi.org/10.1007/978-88-470-5421-9.

Ellis, C. A., \& Parbery, S. A. (2005). Is smarter better? A comparison of adaptive, and simple moving average trading strategies. Research in International Business and Finance, 19(3), 399-411. http://dx.doi.org/10.1016/j.ribaf.2004.12.009.

Fabozzi, F. J., Focardi, S., \& Jonas, C. (2007). Trends in quantitative equity management: Survey results. Quantitative Finance, 7(2), 115-122. http://dx.doi.org/ $10.1080 / 14697680701195941$.

Fama, E. F. (1970). Efficient capital markets: A review of theory and empirical work. The Journal of Finance, 25(2), 383-417. http://dx.doi.org/10.1111/j.15406261.1970 .tb00518.x.

Fama, E. F. (1991). Efficient Capital Markets: II. The Journal of Finance, 46(5), 1575-1617. http://dx.doi.org/10.1111/j.1540-6261.1991.tb04636.x.

Fama, E. F., \& Blume, M. E. (1966). Filter rules and stock-market trading. Journal of Business, 39(1), 226-241. Part 2: Supplement on Security Pricing.

Fong, W. M., \& Yong, L. H. (2005). Chasing trends: Recursive moving average trading rules and internet stocks. Journal of Empirical Finance, 12(1), 43-76. http://dx.doi.org/10.1016/j.jempfin.2003.07.002.

Framinan, J. M., Nagano, M. S., \& Moccellin, J. a. V. (2009). An efficient heuristic for total flowtime minimisation in no-wait flowshops. The International Journal of Advanced Manufacturing Technology, 46(9-12), 1049-1057. http://dx.doi.org/10.1007/s00170-009-2154-0.

Glen, J. (2002). Devaluations and emerging stock market returns. Emerging Markets Review, 3(4), 409-428. http://dx.doi.org/10.1016/S1566-0141(02)000444.

Grossman, S. J., \& Stiglitz, J. E. (1980). On the impossibility of informationally efficient markets. The American Economic Review, 70(3), 393-408.

Han, Y., Yang, K., \& Zhou, G. (2013). A new anomaly: The cross-sectional profitability of technical analysis. Journal of Financial and Quantitative Analysis, 48 (05), 1433-1461. http://dx.doi.org/10.1017/s0022109013000586.

Hoffmann, A. O., \& Shefrin, H. (2014). Technical analysis and individual investors. Journal of Economic Behavior \& Organization. http://dx.doi.org/10.1016/ j.jebo.2014.04.002 (in press) Corrected Proof.

Hsu, P.-H., Hsu, Y.-C., \& Kuan, C.-M. (2010). Testing the predictive ability of technical analysis using a new stepwise test without data snooping bias. Journal of Empirical Finance, 17(3), 471-484. http://dx.doi.org/10.1016/j.jempfin.2010.01.001.

Hudson, R., Dempsey, M., \& Keasey, K. (1996). A note on the weak form efficiency of capital markets: The application of simple technical trading rules to UK stock prices - 1935 to 1994. Journal of Banking E Finance, 20(6), 1121-1132. http://dx.doi.org/10.1016/0378-4266(95)00043-7.

Jaekle, U., \& Tomasini, E. (2009). Trading systems: A new approach to system development and portfolio optimisation. Hampshire: Harriman House LTD.

Jensen, M. C., \& Benington, G. A. (1970). Random walks and technical theories: Some additional evidence. The Journal of Finance, 25(2), 469-482. http://dx. doi.org/10.1111/j.1540-6261.1970.tb00671.x.

Kearney, C. (2012). Emerging markets research: Trends, issues and future directions. Emerging Markets Review, 13(2), 159-183. http://dx.doi.org/10.1016/j. ememar.2012.01.003.

Kissell, R. (2013). The science of algorithmic trading and portfolio management. No. 978-0-12-401689-7. San Diego, California, United States: Academic Press.

Kuo, G. W. (2002). Advanced Trading Rules. In Some exact results for moving-average tranding rules with applications to UK indices, pp. 152-173). ButterworthHeinemann.

Kwon, K.-Y., \& Kish, R. J. (2002). A comparative study of technical trading strategies and return predictability: An extension of using NYSE and NASDAQ indices. The Quarterly Review of Economics and Finance, 42(3), 611-631. http://dx.doi.org/10.1016/S1062-9769(01)00089-8.

Levy, R. A. (1967). Relative strength as a criterion for investment selection. The Journal of Finance, 22(4), 595-610. http://dx.doi.org/10.1111/j.15406261.1967.tb00295.x.

Li, W.-X., Chen, C. C.-S., \& French, J. J. (2012). The relationship between liquidity, corporate governance, and firm valuation: Evidence from Russia. Emerging Markets Review, 13(4), 465-477. http://dx.doi.org/10.1016/j.ememar.2012.07.004.

Lo, A. W. (2004). The adaptive markets hypothesis. Portfolio management, 30(5), 15-29. http://dx.doi.org/10.3905/jpm.2004.442611.

Lo, A. W., \& MacKinlay, A. C. (1988). Stock market prices do not follow random walks: Evidence from a simple specification test. The Review of Financial Studies, 1(1), 41-66. <www.jstor.org/stable/2962126>.

Lo, A. W., Mamaysky, H., \& Wang, J. (2000). Foundations of technical analysis: Computational algorithms, statistical inference, and empirical implementation. The Journal of Finance, 55(4), 1705-1770. http://dx.doi.org/10.1111/0022-1082.00265.

Lo, A. W., \& Wang, J. (1995). Implementing option pricing models when asset returns are predictable. The Journal of Finance, 50(1), 87-129. http://dx.doi.org/ 10.1111/j.1540-6261.1995.tb05168.x.

Manahov, V., Hudson, R., \& Gebka, B. (2014). Does high frequency trading affect technical analysis and market efficiency? And if so, how? Journal of International Financial Markets, Institutions and Money, 28(1), 131-157. http://dx.doi.org/10.1016/j.intfin.2013.11.002.

Marshall, B. R., \& Cahan, R. H. (2005). Is technical analysis profitable on a stock market which has characteristics that suggest it may be inefficient? Research in International Business and Finance, 19(3), 384-398. http://dx.doi.org/10.1016/j.ribaf.2005.05.001.

Mensi, W., Hammoudeh, S., Reboredo, J. C., \& Nguyen, D. K. (2014). Do global factors impact BRICS stock markets? A quantile regression approach. Emerging Markets Review, 19(1), 1-17. http://dx.doi.org/10.1016/j.ememar.2014.04.002.

Metghalchi, M., Chang, Y.-H., \& Marcucci, J. (2008). Is the Swedish stock market efficient? Evidence from some simple trading rules. International Review of Financial Analysis, 17(3), 475-490. http://dx.doi.org/10.1016/j.irfa.2007.05.001.

Mobarek, A., \& Fiorante, A. (2014). The prospects of BRIC countries: Testing weak-form market efficiency. Research in International Business and Finance, 30 (1), 217-232. http://dx.doi.org/10.1016/j.ribaf.2013.06.004.

Moon, Y.-S., \& Kim, J. (2007). Efficient moving average transform-based subsequence matching algorithms in time-series databases. Information Sciences, 177(23), 5415-5431. http://dx.doi.org/10.1016/j.ins.2007.05.038. 
Murphy, J. J. (1999). Technical analysis of the financial markets: A comprehensive guide to trading methods and applications. New York Institute of Finance Series. New York Institute of Finance.

Nagano, M. S., da Silva, A. A., \& Lorena, L. A. N. (2012). A new evolutionary clustering search for a no-wait flow shop problem with set-up times. Engineering Applications of Artificial Intelligence, 25(6), 1114-1120. http://dx.doi.org/10.1016/j.engappai.2012.05.017.

Parisi, F., \& Vasquez, A. (2000). Simple technical trading rules of stock returns: evidence from 1987 to 1998 in Chile. Emerging Markets Review, 1(2), $152-164$. http://dx.doi.org/10.1016/S1566-0141(00)00006-6.

Park, C.-H., \& Irwin, S. H. (2007). What do we know about the profitability of technical analysis? Journal of Economic Surveys, 21(4), 786-826. http://dx.doi. org/10.1111/j.1467-6419.2007.00519.x.

Pavlov, V., \& Hurn, S. (2012). Testing the profitability of moving-average rules as a portfolio selection strategy. Pacific-Basin Finance Journal, 20(5), 825-842. http://dx.doi.org/10.1016/j.pacfin.2012.04.003.

Ratti, R. A., \& Vespignani, J. L. (2015). Commodity prices and BRIC and G3 liquidity: A SFAVEC approach. Journal of Banking E' Finance, 53(1), 18-33. http://dx. doi.org/10.1016/j.jbankfin.2014.12.013.

Reitz, S. (2006). On the predictive content of technical analysis. The North American Journal of Economics and Finance, 17(2), 121-137. http://dx.doi.org/ 10.1016/j.najef.2005.02.001.

Sinkovics, R. R., Yamin, M., Nadvi, K., \& Zhang, Y. Z. (2014). Rising powers from emerging markets-The changing face of international business. International Business Review, 23(4), 675-679. http://dx.doi.org/10.1016/j.ibusrev.2014.04.001.

Sobreiro, V. A., Mariano, E. B., \& Nagano, M. S. (2013). Product mix: The approach of throughput per day. Production Planning E Control, $25(12), 1015-1027$. http://dx.doi.org/10.1080/09537287.2013.798705.

Sobreiro, V. A., \& Nagano, M. S. (2012). A review and evaluation on constructive heuristics to optimise product mix based on the theory of constraints. International Journal of Production Research, 50(20), 5936-5948. http://dx.doi.org/10.1080/00207543.2011.638940.

Taylor, M. P., \& Allen, H. (1992). The use of technical analysis in the foreign exchange market. Journal of International Money and Finance, 11(3), 304-314. http://dx.doi.org/10.1016/0261-5606(92)90048-3.

Teixeira, L. A., \& de Oliveira, A. L. I. (2010). A method for automatic stock trading combining technical analysis and nearest neighbor classification. Expert Systems with Applications, 37(10), 6885-6890. http://dx.doi.org/10.1016/j.eswa.2010.03.033.

Tung, W., \& Quek, C. (2011). Financial volatility trading using a self-organising neural-fuzzy semantic network and option straddle-based approach. Expert Systems with Applications, 38(5), 4668-4688. http://dx.doi.org/10.1016/j.eswa.2010.07.116.

Vanstone, B., \& Finnie, G. (2009). An empirical methodology for developing stockmarket trading systems using artificial neural networks. Expert Systems with Applications, 36(3), 6668-6680. http://dx.doi.org/10.1016/j.eswa.2008.08.019.

Wei, L.-Y., Cheng, C.-H., \& Wu, H.-H. (2014). A hybrid ANFIS based on n-period moving average model to forecast TAIEX stock. Applied Soft Computing, 19, 86-92. http://dx.doi.org/10.1016/j.asoc.2014.01.022.

Zhu, Y., \& Zhou, G. (2009). Technical analysis: An asset allocation perspective on the use of moving averages. Journal of Financial Economics, 92(3), 519-544. http://dx.doi.org/10.1016/j.jfineco.2008.07.002. 